\title{
Oleic Acid Counters Impaired Blastocyst Development Induced by Palmitic Acid During Mouse Preimplantation Development: Understanding Obesity-Related Declines in Fertility
}

\author{
Maisoon D. Yousif ${ }^{1,2,3} \cdot$ Michele D. Calder ${ }^{1,2,3} \cdot$ Jin Tong Du ${ }^{1,2,3} \cdot$ Kelsey N. Ruetz ${ }^{2} \cdot$ Kylie Crocker $^{1,2,3} \cdot$ \\ Brad L. Urquhart ${ }^{2} \cdot$ Dean H. Betts ${ }^{1,2,3} \cdot$ Basim Abu Rafea ${ }^{1} \cdot$ Andrew J. Watson $^{1,2,3}$ iD
}

Received: 28 November 2019 / Accepted: 25 May 2020 / Published online: 15 June 2020

(C) The Author(s) 2020

\begin{abstract}
Obesity is associated with altered fatty acid profiles, reduced fertility, and assisted reproductive technology (ART) success. The effects of palmitic acid (PA), oleic acid (OA), and their combination on mouse preimplantation development, endoplasmic reticulum (ER) stress pathway gene expression, lipid droplet formation, and mitochondrial reactive oxygen species (ROS) were characterized. Twocell stage mouse embryos collected from superovulated and mated CD1 females were placed into culture with KSOMaa medium, or $\mathrm{PA}$ alone or in combination with OA for $46 \mathrm{~h}$. PA significantly reduced blastocyst development in a concentration-dependent manner, which was prevented by co-treatment with OA. PA and OA levels in mouse reproductive tracts were assessed by liquid chromatography coupled to mass spectrometry (LC-MS). LC-MS indicated higher concentrations of PA in the mouse oviduct than the uterus. Transcript analysis revealed that PA alone groups had increased ER stress pathway (ATF3, CHOP, and XBP1 splicing) mRNAs, which was alleviated by OA co-treatment. OA co-treatment significantly increased lipid droplet accumulation and significantly decreased mitochondrial ROS from PA treatment alone. PA treatment for only $24 \mathrm{~h}$ significantly reduced its impact on blastocyst development from the 2-cell stage. Thus, PA affects ER stress pathway gene expression, lipid droplet accumulation, and mitochondrial ROS in treated preimplantation embryos. These mechanisms may serve to offset free fatty acid exposure effects on preimplantation development, but their protective ability may be overwhelmed by elevated PA.
\end{abstract}

Keywords Preimplantation development $\cdot$ Free fatty acids $\cdot$ ER stress $\cdot$ Blastocyst $\cdot$ Fertility

\section{Introduction}

Global obesity is increasing rapidy [1]. In 2017, Statistics Canada reported that 1.87 million and 1.61 million women of reproductive age (18-49 years old) were overweight or obese, respectively [2]. Obesity increases disease risk and infertility in both males [3] and females [4]. Given that obese women have greater difficulty conceiving, they are more
Andrew J. Watson

awatson@uwo.ca

Maisoon D. Yousif

myousif5@uwo.ca

Michele D. Calder

Michele.Calder@schulich.uwo.ca

Jin Tong Du

jdu82@uwo.ca

Kelsey N. Ruetz

kruetz2021@meds.uwo.ca

Kylie Crocker

kcrocker2020@meds.uwo.ca
Brad L. Urquhart

Brad.Urquhart@schulich.uwo.ca

Dean H. Betts

Dean.Betts@schulich.uwo.ca

Basim Abu Rafea

BasimAbuRafea@lhsc.on.ca

Department of Obstetrics and Gynaecology, The University of Western Ontario, London, Ontario N6A 5C1, Canada

2 Department of Physiology and Pharmacology, The University of Western Ontario, London, Ontario N6A 5C1, Canada

3 The Children's Health Research Institute - Lawson Health Research Institute, London, Ontario N6C 2R5, Canada 
likely to seek fertility treatments and make use of assisted reproductive technologies (ARTs). Unfortunately, studies report substantially poorer outcomes for obese women seeking the assistance of fertility treatments [5-8]. Obese women display decreased responses to gonadotropins used for ovarian stimulation and thus require higher doses of hormones when undergoing ovarian stimulation [7,9]. With increasing body mass index (BMI), the number of oocytes successfully collected decreases $[9,10]$. Thus, regardless of increased gonadotropin doses, obesity is associated with significantly greater risk of unsuccessful ovarian stimulation cycles [7]. In vitro fertilization (IVF) or intracytoplasmic sperm injection (ICSI) in obese women does not affect their ability to become clinically pregnant [8]; however, obese women are at a higher risk for early and recurrent pregnancy loss $[9,11]$ and miscarriage [8]. During pregnancy, obese women have a higher prevalence of gestational diabetes [11]. Additionally, live birth frequencies are reduced with obesity [7]. The mechanisms underlying the negative direct effects of obesity on reproduction are not fully understood and must be investigated to assist this rapidly growing patient population.

Non-esterified fatty acids (NEFAs) are free fatty acid (FFA) molecules found primarily bound to albumin in circulation [12]. High BMI is associated with elevated NEFA levels in vivo [13]. Palmitic acid (16:0, PA) is the most abundant NEFA in circulation [14], and in the Western diet [15]. Oleic acid $(18: 1, \mathrm{OA})$ is the most abundant monounsaturated NEFA in human serum [14]. Concentrations of free PA and $\mathrm{OA}$ are between 50 and $70 \mu \mathrm{M}$ in human follicular fluid and increase in obese women [16]. Although PA concentrations in the human female reproductive tract remain unknown, its presence in serum and follicular fluid suggests that PA and $\mathrm{OA}$ are the primary FFAs that embryos are exposed to during preimplantation development. Although PA and OA structurally differ by only two carbons and a double bond, these FFAs have very different metabolic fates [17]. PA, but not OA, is associated with higher diabetes risk [18]. PA displays greater incorporation into phospholipids, and increased lipogenesis, increased beta oxidation, and reduced oxidative phosphorylation than OA does [17].

Exposure to maternal high-fat diet in vivo significantly lowers development of mouse embryos to the blastocyst stage [19]. In mice, transfer of blastocysts from mothers fed a highfat diet into control normal weight recipients still results in fetal growth restriction and brain developmental abnormalities, indicating that the underlying origin of the problem occurs due to exposure to a high-fat environment during gametogenesis and/or preimplantation development [19]. Increased FFAs in human follicular fluid are correlated with poor cumulus-oocyte-complex (COC) quality [20]. Treatment of bovine COCs with FFAs impairs blastocyst development; however, rescue by the unfolded protein response (UPR)/endoplasmic reticulum (ER) stress pathway inhibitor salubrinal identified UPR activation as a major contributor to FFAdependent developmental decreases [21]. Studies conducted over the past decade have indicated that the preimplantation embryo is armed with several key stress response mechanisms that, in part, offset the deleterious effects of stress on early development (for review see [22, 23]). Most notably, these are the ER stress pathways, which oversee the unfolded protein response (UPR) and activate stress-responsive gene expression patterns in an attempt to allow the early embryo to effectively adapt to and survive both external and internal stressors [22, 23]. Studies, including ours, have demonstrated the presence and action of ER stress pathways throughout preimplantation development [24-27]. To date, however, studies have not investigated the influences of free fatty acid treatment, i.e., PA and OA on ER stress pathway constituents, and we postulate that differential responses to PA and OA treatment should occur during preimplantation development.

Investigating the direct effects of FFAs on preimplantation embryos in vitro is required to define the mechanistic consequences of exposure to PA and OA, in isolation and in combination, on mammalian preimplantation embryo development in general. We must also learn how the high-fat environment in an obese patient affects preimplantation development. Ultimately, research should inform how the in vitro culture environment can be modified to alleviate deleterious effects of FFA exposure on not only early development but also its longer-term effects on pregnancy, on fetal development, and throughout life. In this study, we report outcomes from experiments in which 2-cell stage mouse embryos were treated with increasing concentrations of PA or OA alone and in combination. We report the effects of these treatments on preimplantation development, ER stress pathway gene expression, lipid droplet formation, and mitochondrial reactive oxygen species (ROS) generation. In addition, we report PA and OA concentrations in the mouse oviduct and uterus. Our outcomes reveal that the PA treatment reduces blastocyst development and alters ER stress pathway transcript levels. OA co-treatment with PA not only reverses PA effects on blastocyst development and ER stress transcript levels but also increases lipid droplet formation and reduces mitochondrial stress. We conclude that preimplantation embryos do employ stress response mechanisms to avoid deleterious effects of PA exposure, but their protective ability may be overwhelmed by exposure to elevated PA.

\section{Materials and Methods}

\section{Animal Source and Ethics Approval}

All experiments were performed using CD-1 mice from Charles River Laboratories (Saint-Constant, QC). All mice were handled according to the Canadian Council on Animal 
Care and Western University's Animal Care and Use Policies (protocol \#: 2018-075 to Dr. Andrew J. Watson). Mice were housed using conventional housing with a 12-h light/dark cycle and access to standard mouse chow ad libitum.

\section{Liquid Chromatography Mass Spectrometry Analysis of Oviduct and Uterine PA and OA}

Oviduct and uterine concentrations of free PA and OA were quantified using Ultra Performance Liquid Chromatography (UPLC) coupled to quadrupole time of flight (QToF) mass spectrometry. Pairs of ovaries and uterine horns were carefully dissected free of visible fat, placed into cryovials, and frozen over liquid nitrogen before storing at $-80{ }^{\circ} \mathrm{C}$. Following thawing, ovaries or uteri were weighed and $200 \mu \mathrm{L}$ of acetonitrile containing labeled PA and OA (internal standards, $50 \mu \mathrm{g} / \mathrm{mL}$ each) was added to each sample. Samples were homogenized and incubated on ice for $20 \mathrm{~min}$. Samples were then centrifuged at $20,800 \times g$, and the clear supernatant was transferred to a clean glass vial. Analytes were separated using a Phenomenex Phenyl-Hexyl column, $2.1 \times 100 \mathrm{~mm}, 1.7 \mu$ using a Waters Acquity UPLC (Milford, MA) maintained at $40^{\circ} \mathrm{C}$. The mobile phases consisted of water with $0.1 \%$ formic acid (A) and acetonitrile with $0.1 \%$ formic acid (B) and were pumped across the column at $0.5 \mathrm{~mL} / \mathrm{min}$. The gradient was as follows: from 0 to $1.5 \mathrm{~min}$, the gradient went from $80 \mathrm{~B}$ to $99 \% \mathrm{~B}$ and was held at $99 \% \mathrm{~B}$ from 1.5 to $2.0 \mathrm{~min}$. The column was reconditioned with $80 \%$ B for 1 min before injecting the next sample. The mass spectrometer used was a Waters Xevo G2-S QToF operated in negative ionization mode with the following parameters: capillary voltage, $2 \mathrm{kV}$; cone voltage, $40 \mathrm{~V}$; source temperature, $150{ }^{\circ} \mathrm{C}$; desolvation temperature, $500{ }^{\circ} \mathrm{C}$; desolvation gas flow, $1000 \mathrm{~L} / \mathrm{h}$. Data were acquired using MSe in resolution mode with a scan time of $0.05 \mathrm{~s}$ and a mass range of $50-1200 \mathrm{~m} / \mathrm{z}$. The mass accuracy of the instrument was maintained by infusing leucine-enkephalin $(1 \mathrm{ng} / \mu \mathrm{L})$ as the lockspray, which was acquired, every $10 \mathrm{~s}$ with a scan time of $0.3 \mathrm{~s}$, which were averaged over 3 scans.

\section{Mouse Superovulation and Mating}

Four- to six-week-old female CD-1 mice were intraperitoneally (IP) injected with 7.5 international units (IU) of pregnant mare's serum gonadotropin (PMSG, Merck Animal Health, Canada) to stimulate follicular development. Forty-eight hours later, these same females were IP injected with 7.5-IU human chorionic gonadotropin (hCG, Merck Animal Health, Canada) to stimulate ovulation. Immediately after hCG injection, each female was placed in a cage with a single male CD1 mouse (6-8 months of age) for mating overnight. The following morning, female mice were checked for presence of a seminal plug. Forty-six hours post-injection (hpi) of hCG, female mice were euthanized by $\mathrm{CO}_{2}$ asphyxiation (standard operating procedure) and had their oviducts removed and flushed with room temperature M2 flushing medium (Sigma-Aldrich, Oakville, ON) [28-30]. Flushed 2-cell stage embryos were washed $3 \times$ in $50-\mu \mathrm{L}$ drops of potassium simplex optimization medium with amino acids (KSOMaa Evolve, Zenith Biotech, Canada). After washing, embryos were distributed equally among experimental treatment groups and cultured in $20-\mu \mathrm{L}$ drops under mineral oil (Zenith Biotech, Canada) at a density of 1 embryo per microliter for $46 \mathrm{~h}$ under a $5 \% \mathrm{CO}_{2}, 5 \% \mathrm{O}_{2}$, and $90 \% \mathrm{~N}_{2}$ culture atmosphere.

\section{Free Fatty Acid Preparation and Embryo Culture}

Essentially FFA-free bovine serum albumin (BSA, SigmaAldrich, Oakville ON) was added to phosphate buffered saline (PBS) and dissolved overnight to create a 20\% BSA solution. This solution was filter sterilized and used downstream for conjugation to PA (Sigma-Aldrich, Oakville ON) or OA (Sigma-Aldrich, Oakville, ON). Stock PA and OA solutions were prepared by solubilizing each FFA in RNAse-free water and $\mathrm{NaOH}$ at $70{ }^{\circ} \mathrm{C}$ to create a $20-\mathrm{mM}$ solution. This stock sample was conjugated in a 2:1 molar ratio to BSA to create a final $500-\mu \mathrm{M}$ FFA solution that was stored at $4{ }^{\circ} \mathrm{C}$. Experiments were performed where 2-cell stage embryos were cultured in FFA conjugated 2:1 to BSA in KSOMaa.

\section{PA and OA Concentration Response and Treatment Experiments}

We first defined the concentration effects of PA and OA treatments alone on development of 2-cell stage embryos to the blastocyst stage. The treatment concentration series for PA consisted of 25,50 , and $100 \mu \mathrm{M}$, and for OA was 50, 100, 250 , and $500 \mu \mathrm{M}$. For each experimental replicate and treatment group, twenty 2-cell embryos were placed into $20-\mu \mathrm{L}$ drops of the appropriate treatment medium covered by embryo-grade mineral oil (Zenith Biotech, Canada). Embryos were cultured under a $5 \% \mathrm{CO}_{2}, 5 \% \mathrm{O}_{2}$, and $90 \%$ $\mathrm{N}_{2}$ atmosphere at $37{ }^{\circ} \mathrm{C}$ for $46 \mathrm{~h}$ to assess progression to the blastocyst stage.

Once effects of single PA and OA treatment on development was characterized, we proceeded with conducting single treatment and PA and OA combination treatment experiments. Treatments included control (+1.5\% BSA); $100-\mu \mathrm{M}$ PA alone; or $100-\mu \mathrm{M}$ PA with either $50-; 100-$, or $250-\mu \mathrm{M}$ OA in combination in KSOMaa. The BSA content was controlled between treatments using a 1.5\% BSA in KSOMaa control, which was prepared from the original $20 \%$ BSA solution. For each experimental replicate and treatment group, twenty 2-cell embryos were placed into $20-\mu \mathrm{L}$ drops of the appropriate treatment medium covered by embryo-grade 
mineral oil (Zenith Biotech, Canada). Embryos were cultured under a $5 \% \mathrm{CO}_{2}, 5 \% \mathrm{O}_{2}$, and $90 \% \mathrm{~N}_{2}$ atmosphere at $37^{\circ} \mathrm{C}$ for $46 \mathrm{~h}$ to assess progression to the blastocyst stage.

To assess the effect of PA treatment time on development to the blastocyst stage, twenty 2-cell embryos were placed in control media or $100-\mu \mathrm{M}$ PA treatment media for $24-\mathrm{h}$ culture, and then embryos were washed and placed into PA-free control medium for either 24 or 48 additional hours of culture, leaving the embryos in culture for a total of 48 and $72 \mathrm{~h}$, respectively. Blastocyst development was assessed at the end of the 48- and 72-h culture periods.

\section{Developmental Stage Analysis}

At the end of each experimental replicate culture period, embryos were examined under a light-dissecting microscope. The proportion of embryos at each stage of preimplantation development was recorded. Embryos were classified as either a blastocyst, morula (compacted embryo), 8-cell, 4-cell, 2cell, or degenerated embryo. Morulae were defined as embryos where distinct blastomeres could not be identified or counted, but no visible fluid-filled cavity was apparent. Blastocysts were defined as any embryo with a visible fluid-filled cavity. After developmental analysis, embryos were either snap frozen at $-80^{\circ} \mathrm{C}$ for RNA extraction or fixed for future staining and confocal microscopy.

\section{RNA Extraction and Reverse Transcription}

The ARCTURUS PicoPure RNA Isolation Kit (Life Technologies, Burlington, $\mathrm{ON}$ ) was used per the manufacturer protocol to extract total RNA from pools of 20 preimplantation mouse embryos in each sample and replicate [30]. Exogenous luciferase mRNA (0.025 pg/embryo, Promega, USA) was added for use as a reference standard gene when analyzing mRNA quantities using the delta delta cycle threshold $\left(2^{-\Delta \mathrm{Ct}}\right)$ method. To eliminate genomic DNA, DNase 1 (RNA-free DNase kit, Qiagen, Louisville, KY) was added in an additional step. The VILO cDNA Synthesis Kit (Invitrogen, Burlington, $\mathrm{ON}$ ) was used according to the manufacturer protocol to reverse transcribe the extracted RNA into cDNA. cDNA was diluted to 1 embryo/ $\mu \mathrm{L}$ in PCR-grade water.

\section{XBP1 Spliced and Unspliced Transcript Detection}

To confirm the effectiveness/quality of cDNA synthesis, polymerase chain reaction (PCR) was performed for H2A and luciferase on each embryo reverse transcribed sample. Each reaction included $2.5 \mu \mathrm{L}$ of $10 \mathrm{X}$ PCR buffer, $0.75-\mu \mathrm{L} \mathrm{MgCl}_{2}$, $0.5-\mu \mathrm{L}$ dNTPs, $0.1 \mu \mathrm{L}$ each of the forward and reverse primer, $0.2-\mu \mathrm{L}$ Taq polymerase, and $19.85-\mu \mathrm{L}$ RNase-free water. The cycling conditions for both $\mathrm{H} 2 \mathrm{~A}$ and luciferase were $94{ }^{\circ} \mathrm{C}$ for
2 min, followed by 44 cycles of $94^{\circ} \mathrm{C}$ for $30 \mathrm{~s}, 61^{\circ} \mathrm{C}(\mathrm{H} 2 \mathrm{~A})$ or $59{ }^{\circ} \mathrm{C}$ (luciferase) for $30 \mathrm{~s}, 72{ }^{\circ} \mathrm{C}$ for $1 \mathrm{~min}$, and a last step of $72{ }^{\circ} \mathrm{C}$ for $10 \mathrm{~min}$. PCR products were run on a $2 \%$ agarose gel for $\mathrm{H} 2 \mathrm{~A} /$ luciferase with ethidium bromide in TAE running buffer at $100 \mathrm{~V}$ for $1 \mathrm{~h}$, after which the gel was imaged. For XBP1 mRNA transcript detection, cycling conditions were $94{ }^{\circ} \mathrm{C}$ for 2 min, followed by 45 cycles of $94{ }^{\circ} \mathrm{C}$ for $30 \mathrm{~s}$, $61{ }^{\circ} \mathrm{C}$ for $30 \mathrm{~s}, 72{ }^{\circ} \mathrm{C}$ for $1 \mathrm{~min}$, and a last step of $72^{\circ} \mathrm{C}$ for $10 \mathrm{~min}$. XBP1 PCR products were run on a $4 \%$ agarose gel with TBE running buffer at $60 \mathrm{~V}$ for $3 \mathrm{~h}$. Positive controls contained cDNA from embryos that were treated with the potent and reliable ER stress inducer tunicamyin [31], while negative controls included RNase-free water in place of cDNA. Splicing of XBP1 was quantified using the ImageJ software on three biological replicates.

\section{Quantitative RT-PCR Assessment of ATF3, CHOP, and ATF6, Transcripts}

Quantitative RT-PCR was performed using Taqman primer probes (Invitrogen, Canada) for target genes in a 384-well plate. Master mix (MM) of TaqMan Gene Expression Mastermix (volume $=0.5 \times$ total volume $(\mathrm{V})$ ), TaqMan primer probe (volume $=0.05 \times \mathrm{V})$, and RNase-free water (volume $=0.4 \times \mathrm{V}$ ) were prepared and $62.7 \mu \mathrm{L}$ aliquoted into Eppendorf tubes, to which $3.3 \mu \mathrm{L}$ (equivalent to 1 embryo/ $\mu \mathrm{L}$ ) of embryo cDNA was added. This mixture of master mix and cDNA was vortexed, and $20 \mu \mathrm{L}$ was added in triplicate wells to the PCR plate. For each experimental series, a negative no transcript control was included, where RNase-free water replaced the cDNA. Using a BioRad CFX384 Touch ${ }^{\mathrm{TM}}$ Real-Time PCR Detection System, quantitative RT-PCR (qPCR) was run according to the following conditions: $5 \mathrm{~min}$ at $95^{\circ} \mathrm{C}$ (AmpliTaq GOLD DNA polymerase activation step), followed by $50 \mathrm{cy}-$ cles of $15 \mathrm{~s}$ at $95{ }^{\circ} \mathrm{C}$ (denaturation) and $1 \mathrm{~min}$ at $60{ }^{\circ} \mathrm{C}$ (annealing and extension). To assess ER stress, primer probes for ATF3 (Mm00476032_m1), CHOP (Mm01135937_g1 Ddit3), and ATF6 (Mm01295317_m1 Atf6) were used. Three biological replicates were assessed for each gene, for each treatment, and for each experimental replicate.

\section{BODIPY 493/503 Staining to Assess Embryo Lipid Droplet Accumulation}

After the 46-h culture treatment period, embryos from treatment and control were placed in 2\% paraformaldehyde in PBS for $30 \mathrm{~min}$ for fixing. They were then washed $3 \mathrm{X}$ in PBS and stored at $4{ }^{\circ} \mathrm{C}$. BODIPY (ThermoFisher Scientific, Mississauga, $\mathrm{ON}$ ) was solubilized in DMSO to a concentration of $2.5 \mathrm{mg} / \mathrm{mL}$ to create a stock solution, and an aliquot was diluted to $20 \mu \mathrm{g} / \mathrm{mL}$ using the KSOMaa medium. Embryos from all treatment groups, except the negative control, were placed in $20-\mu \mathrm{L}$ drops of BODIPY solution covered 
in embryo-grade mineral oil for $1 \mathrm{~h}$ at room temperature. Embryos were then washed $3 \times$ in PBS and added to $10-\mu \mathrm{L}$ drops of PBS covered in mineral oil in a glass-bottom dish. An independent group of embryos exposed to OA at varying concentrations was used to set the laser intensity (Alexa Fluor 488). Embryos were imaged using confocal microscopy (Zeiss LSM800 microscope) at $\times 10$ magnification. Z-stacks were imaged in $5-\mu \mathrm{m}$ slices. Images were processed using the FIJI and Ilastik software [32]. Within a group, each embryo was defined as a biological replicate. The fluorescence intensity of each individual embryo in each treatment group was quantified to determine mean fluorescence within a treatment group using the Ilastik software.

\section{MitoSox $^{\mathrm{TM}}$ Red Superoxide Stain}

MitoSox ${ }^{\mathrm{TM}}$ Red mitochondrial superoxide indicator (Life Technologies, Burlington, ON) was solubilized in DMSO and diluted using KSOMaa to a concentration of $5 \mu \mathrm{M}$. Culture dishes were prepared with $20-\mu \mathrm{L}$ drops of this solution covered in embryo-grade mineral oil. Live embryos were incubated in this solution for $1 \mathrm{~h}$ at $37{ }^{\circ} \mathrm{C}, 5 \% \mathrm{O}_{2}, 5 \% \mathrm{CO}_{2}$, and $90 \% \mathrm{~N}_{2}$. A no-MitoSox ${ }^{\mathrm{TM}}$ Red negative control was also included. Embryos were then washed $3 \times$ in KSOMaa and added to $10-\mu \mathrm{L}$ drops of KSOMaa in a glass-bottom dish for imaging by confocal microscopy (Zeiss LSM800 microscope) at $\times 10$ magnification. An independent group of embryos exposed to $100-\mu \mathrm{M}$ PA treatment was used to set the confocal laser intensity (Alexa Fluor 568). Z-stacks were imaged in $5-\mu \mathrm{m}$ slices. Images were processed using the FIJI and Ilastik software [32]. Within a group, each embryo was a biological replicate. The fluorescence intensity of each individual embryo in each treatment group was quantified to determine mean fluorescence within a treatment group using the Ilastik software.

\section{Statistical Analyses}

GraphPad PRISM 8 (https://www.graphpad.com/scientificsoftware/prism/) was employed to perform statistical analyses. For analysis of tissue concentrations of PA and OA by mass spectrometry, a two-way analysis of variance (ANOVA) was performed with main factors of age and tissue type and means compared by using Tukey's multiple comparisons tests. For all subsequent experiments, a minimum of three biological replicates was conducted. For imaging studies, a biological replicate was defined as a single embryo within a treatment. However, for assessments of developmental stage and mRNA abundance through qPCR, a biological replicate consisted of a single pool of 20 embryos within a treatment group. Blastocyst development was analyzed using a one-way ANOVA test, and means were compared to one another by an ad hoc Tukey's multiple comparisons test. The same statistical analyses were used when analyzing the number of embryos arrested at different stages of development with the FFA treatments. Using cycle threshold values from qRT-PCR, relative amounts of mRNA were quantified using the delta delta cycle threshold $\left(2^{-\triangle \Delta \mathrm{Ct}}\right)$ method followed by one-way ANOVA and Tukey's multiple comparisons tests. Data analysis for BODIPY and MitoSox ${ }^{\mathrm{TM}}$ Red outcomes included applying one-way ANOVA with Tukey's multiple comparisons tests. For all tests, $p$ values of less than or equal to 0.05 were considered significantly different from one another.

\section{Results}

\section{PA and OA Concentrations in Mouse Oviduct and Uterus}

Table 1 shows the mean \pm standard error (SE) of the mean concentrations of PA and OA that were detected using liquid chromatography mass spectrometry (LC-MS) in whole mouse oviduct (4-week-old mice, $n=9 ; 8$-month-old mice, $n=12$ ) and uterine (4-week-old mice, $n=10$; 8-month-old mice, $n=$ 12) lysates. Values were corrected for tissue weight; pairs of oviducts ranged from 5.1 to $13.3 \mathrm{mg}$, while uteri ranged from 40.1 to $142.1 \mathrm{mg}$. Older mice displayed higher oviduct and uterine weights than 4-week-old mice. In the two-way ANOVA for PA, there was no effect of age or interaction; however, there was a significant effect of tissue type. Oviducts had significantly higher $(p<0.001)$ concentrations of PA than uteri. PA concentrations were significantly higher $(p<0.05)$ than OA concentrations in oviducts and uteri for both age groups. In contrast, for OA, there was a significant interaction of age by tissue $(p<0.02)$, such that young oviducts had lower OA concentrations than older oviducts, or young or older uteri. There were also significant effects of age $(p<0.01)$ and tissue $(p<0.001)$ with uteri having higher average OA concentrations compared with oviducts (Table 1 ).

\section{Concentration-Responsive Effects of PA and OA Treatment on Mouse Preimplantation Development}

The concentration-responsive effects of treating 2-cell stage mouse embryos with increasing doses of PA and OA are shown in Fig. 1. OA concentration, at all doses ( $46 \mathrm{~h}$ of treatment), did not have a significant $(p>0.05)$ effect on the progression of treated embryos to the blastocyst stage (Fig. 1a). PA treatment in contrast resulted in a significant decline $(p<0.05)$ in the progression to the blastocyst stage for concentrations over $25 \mu \mathrm{M}$ (Fig. 1b). This result was accompanied by a corresponding increase in the proportion of early cleavage-stage embryos observed in PA treatment concentrations greater than $50 \mu \mathrm{M}$ (data not shown). Embryos treated 
Table 1 Palmitic acid and oleic acid concentrations in mouse oviduct and uterus

\begin{tabular}{llllll}
\hline & \multicolumn{3}{l}{ Palmitic acid $(\mu \mathrm{M})$} & & \multicolumn{2}{l}{ Oleic acid $(\mu \mathrm{M})$} \\
\cline { 2 - 3 } \cline { 5 - 6 } Mouse groups & Oviduct & & Oviduct & Uterus \\
\hline 4-week CD1 & $377.6 \pm 33.2^{(9)}$ & $192.8 \pm 21.6^{(10)}$ & & $18.0 \pm 4.4^{(9) \mathrm{c}}$ & $51.0 \pm 6.6^{(10) \mathrm{d}}$ \\
8-month CD1 & $404.9 \pm 33.2^{(12)}$ & $145.1 \pm 8.9^{(12)}$ & & $44.3 \pm 3.2^{(12) \mathrm{d}}$ & $51.8 \pm 4.2^{(12) \mathrm{d}}$ \\
Combined values & $393.2 \pm 23.3^{(21) \mathrm{a}^{*}}$ & $166.8 \pm 11.9^{(22) \mathrm{b} \S}$ & & $33.0 \pm 2.4^{(21)^{*}}$ & $51.4 \pm 3.7^{(22) \S}$ \\
\hline
\end{tabular}

$\mathrm{N}$ values in brackets for each group

All values represent mean $\pm \mathrm{SE}$

${ }^{\mathrm{a}, \mathrm{b}}$ Within PA, superscripts denote significant differences between tissues, $p<0.001$

${ }^{\mathrm{c}, \mathrm{d}}$ Within OA, superscripts denote an age by tissue interaction, $p<0.02$

${ }^{*}$ Within oviducts, PA is higher than OA, $p<0.001$

$\S$ Within uteri, PA is higher than OA, $p<0.001$

\section{a}

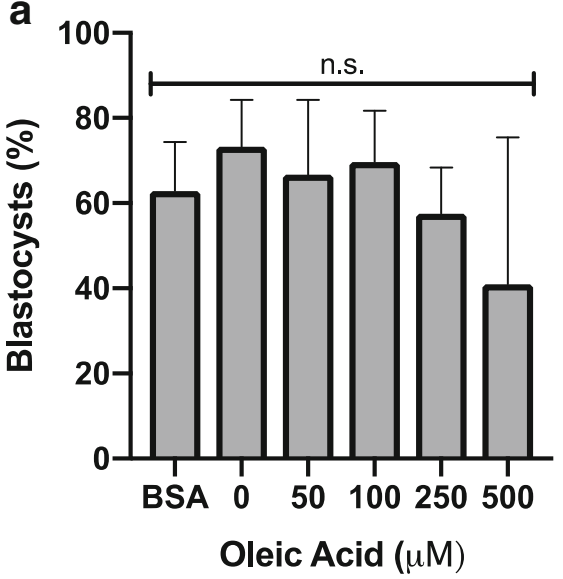

c

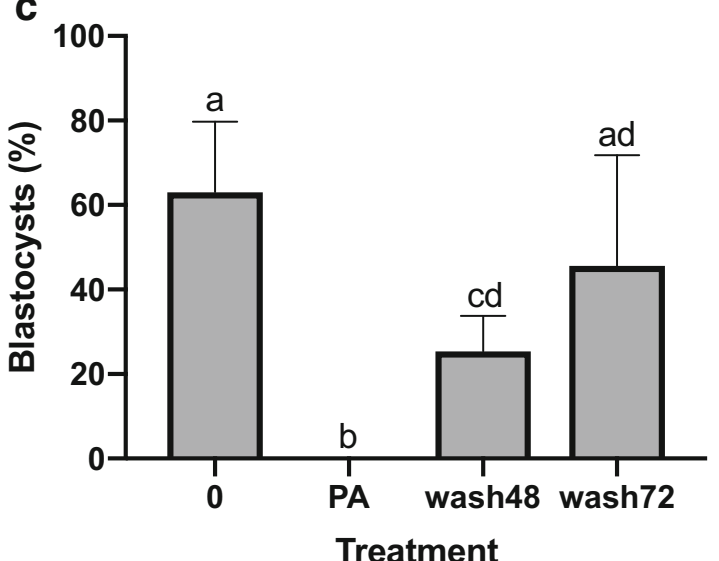

ment
Fig. 1 Concentration-responsive effects of PA and OA on blastocyst development. The percentage of blastocysts after 46-h culture in increasing concentrations of a OA or b PA. Treatment of 2-cell embryos in $1.5 \%$ BSA and at all OA doses did not significantly affect development to the blastocyst stage (a, $p>0.05, n=3$ ). In contrast, treatment with concentrations of PA over $25 \mu \mathrm{M}$ resulted in a significant decline in development to the blastocyst stage (b, $p<0.05$, $n=3$ ). $\mathbf{c}$ Effects of 24-h treatment with 100- $\mathrm{MM}$ PA followed by culture in PA-free control medium for $24 \mathrm{~h}$ (wash48 h) and $48 \mathrm{~h}$ (wash72 h) after b

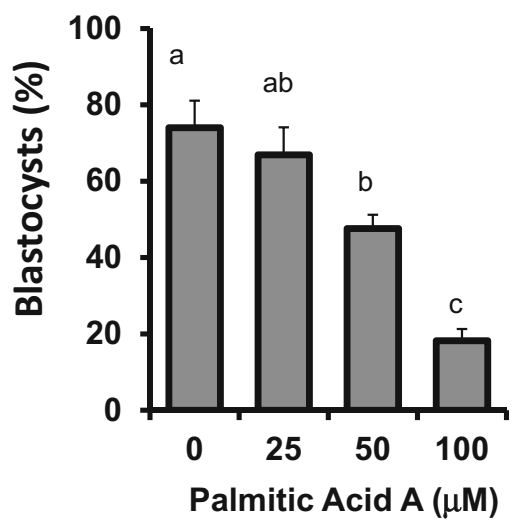

treatment on development from the 2-cell stage. Twenty-four-hour PA treatment (wash48) at the 2-cell stage did not reduce blastocyst development as severely as 46-h PA treatment (PA, c, $n=3-8$ ). In fact, 2 cell embryos treated for $24 \mathrm{~h}$ with $100-\mu \mathrm{M}$ PA and then placed into control medium for $48 \mathrm{~h}$ (wash72) displayed an equivalent level of development to the blastocyst stage as untreated controls (c). Bars represent the mean percentage of embryos at the blastocyst stage + standard deviation (SD) $(\mathbf{a}, \mathbf{b}, \mathbf{c})$. Bars with $p$ values $<0.05$ are statistically significant from one another 
with PA dose higher than $50 \mu \mathrm{M}$ increasingly displayed cell fragmentation and unequal blastomere size (Fig. 2f). However, embryos exposed to OA alone displayed normal morphological characteristics expected for mouse preimplantation embryos at all stages (data not shown). In contrast, 2cell embryos treated with $100-\mu \mathrm{M}$ PA for $24 \mathrm{~h}$ only and then placed into PA-free control medium for $24 \mathrm{~h}$ (for a total of $48 \mathrm{~h}$ of culture) displayed significantly $(p<0.05)$ higher development to the blastocyst stage than that displayed by 46-h PA-treated 2-cell embryos (Fig. 1c, wash48). Furthermore, when 24-h PA-treated 2-cell embryos were cultured in normal control medium for $48 \mathrm{~h}$ after treatment (for a total treatment and culture time of $72 \mathrm{~h}$ ), blastocyst development was no longer significantly different from control levels of development (Fig. 1c, wash72). Since 100- $\mu$ M PA-treated embryos displayed a capacity to recover from treatment, we adopted this PA concentration level as standard for all subsequent experiments. Controls for BSA content $(\mathrm{BSA}=1.5 \% ; 0=$ $1 \mathrm{mg} / \mathrm{ml} \mathrm{BSA}$, Fig. 1a) demonstrated that the BSA content of the medium did not adversely affect development of treated 2-cell embryos to the blastocyst stage.

\section{Effect of PA and OA Co-Treatment on Mouse Preimplantation Development}

To characterize the effects of combined treatment, 2-cell stage embryos were placed into culture in either control medium; medium with 100- $\mu \mathrm{M}$ PA alone; or medium (100- $\mu \mathrm{M}$ PA) in combination with $50-, 100-$, or $250-\mu \mathrm{M}$ OA for $46 \mathrm{~h}$. PA alone significantly reduced development to the blastocyst stage ( $p<0.05$, Fig. $2 \mathrm{~d}$ ), with a corresponding significant increase in the proportion of early cleavage-stage embryos undergoing a developmental arrest before the morula stage $(p<0.05$, Fig. $2 \mathrm{a}-\mathrm{c})$. The proportion of morula-stage embryos did not differ between treatments ( $p>0.05$, Fig. $2 \mathrm{c})$. In complete contrast to the PA alone treatment results, OA cotreatment at all doses $(50-250-\mu \mathrm{M}$ concentrations $(p<0.05$, Fig. 2d)) offsets the PA-induced significant decline in the development of 2-cell stage embryos to the blastocyst stage in vitro. Figure $2 \mathrm{f}$ displays the typical morphology of embryos treated with $100-\mu \mathrm{M}$ PA compared with untreated controls (Fig. 2e) and to that of 2-cell stage embryos co-cultured in 100- $\mu \mathrm{M}$ PA with all OA concentrations (Fig. 2g, PA+OA).

\section{Effects of PA and OA on Preimplantation Embryo ER Stress Pathway Transcripts}

We next characterized the effects of PA and OA treatment on preimplantation development ER stress pathways. To do this, we characterized the effect of 100- $\mathrm{MM}$ PA treatment alone and $\mathrm{PA}$ and $\mathrm{OA}$ combination treatment on transcript levels of markers representing all three main ER stress pathways. ATF3 and CHOP mRNA levels were not significantly affected by OA treatment at any dose (Fig. 3a and b). However, in embryos treated with 100- $\mu$ M PA alone, ATF3 transcript abundance increased significantly $(p<0.05)$ to over 15 fold that of control, and CHOP transcript abundance was also significantly $(p<0.05)$ increased and approached 5-fold greater levels than controls (Fig. $4 \mathrm{a}$ and b). In contrast, OA cotreatment at all doses alleviated the PA-induced increase in CHOP and ATF3 mRNA levels (Fig. 4a and b). Interestingly, PA treatment $(100 \mu \mathrm{M})$ alone or in combination with OA did not significantly affect the relative levels of ATF6 mRNAs across all groups, suggesting that this arm of the UPR may not be influenced by FFA exposure during mouse preimplantation development (Fig. 4c). Investigation of the IRE1 arm of the ER stress pathway required us to measure changes in the proportion of XBP1 spliced and unspliced mRNAs. XBP1 is downstream of IRE1 pathway activation, and its activation is dependent upon transcript splicing, with spliced transcript representing activated XBP1 that serves as a nuclear transcription factor upon activation of ER stress response. Treatment with $100-\mu \mathrm{M}$ PA significantly $(p<0.05)$ increased in XBP1 mRNA splicing (Fig. 5A-C, three separate experimental replicates displayed) relative to controls. In contrast, XBP1 mRNA splicing was significantly reduced $(p<0.05)$ when co-treatment with all OA concentrations was employed (Fig. 5D), while tunicamycin (an ER stress activator)-treated positive $(+)$ controls displayed a significant increase in spliced XBP1 (Fig. 5D).

\section{Effects of $O A$ and PA Treatment on Preimplantation Embryo Lipid Droplet Abundance}

Next, the influence of FFA treatment on lipid droplet (LD) accumulation in mouse preimplantation embryos was characterized. Relative to embryos exposed to control media, OA treatment alone $(100 \mu \mathrm{M})$ significantly increased $(p<0.05$, Fig. $6 \mathrm{Ab}, \mathrm{Bb}$, and $\mathrm{C}$ ) LD content. However, PA treatment $(100 \mu \mathrm{M})$ alone did not significantly affect LD content ( $p>0.05$, Fig. 6Ac, Bc, and C). Co-treatment with $50-\mu \mathrm{M}$ OA (Fig. 6Ad, Bd, and C) also did not significantly alter LD levels from that observed for controls (Fig. 6Aa, Ba, and C), PA alone (Fig. 6Ac, Bc, and C), or 100- $\mu \mathrm{M}$ OA-treated embryos (Fig. 6Ab, Bb, and C). However, OA concentrations of 100 and $250 \mu \mathrm{M}$ in combination with PA $(100 \mu \mathrm{M})$ significantly increased ( $p<0.05$, Fig. $6 \mathrm{Ae}, \mathrm{Be}, \mathrm{Af}, \mathrm{Bf}$, and C) LD levels to 16 and 18 times greater than those of controls, respectively.

\section{Effects of $O A$ and PA Treatment on Preimplantation Embryo on Mitochondrial Superoxide Levels}

We next characterized whether PA $(100 \mu \mathrm{M})$ or OA cotreatment affected preimplantation mouse embryonic mitochondrial superoxide levels, by measuring MitoSox ${ }^{\mathrm{TM}}$ 

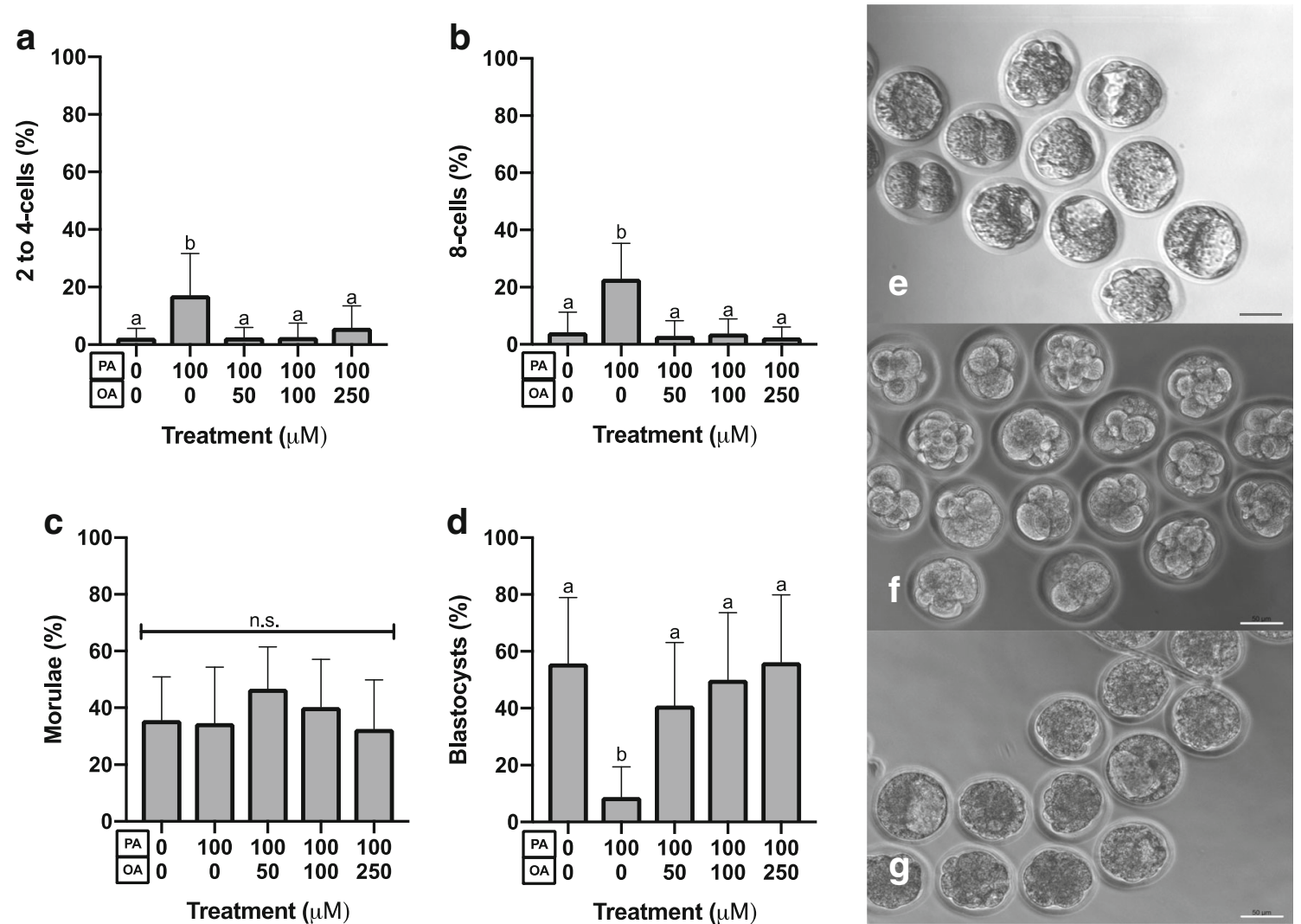

Fig. 2 PA and OA co-treatment effects on blastocyst development. 2-cell stage embryos were placed into culture in either control medium $(n=13)$; $100-\mu \mathrm{M}$ PA alone $(n=13)$; or $100-\mu \mathrm{M}$ PA in combination with $50-(n=$ $10), 100-(n=11)$, or $250-(n=12) \mu \mathrm{M}$ OA. PA alone significantly reduced $(p<0.05)$ development to the blastocyst stage $(\mathbf{d})$, with a corresponding significant increase in the proportion of early cleavagestage embryos undergoing a developmental arrest before the morula stage $(\mathbf{a}-\mathbf{c})$. The proportion of morula did not differ significantly between treatments $(\mathbf{c})$. OA co-treatment at all doses $(50-250-\mu \mathrm{M}$

Red fluorescence. Mitochondrial superoxide produced by embryos exposed to $100-\mu \mathrm{M}$ PA treatment alone (Fig. $7 \mathrm{Ab}, \mathrm{Bb}$, and $\mathrm{C}$ ) or in combination with $50-\mu \mathrm{M}$

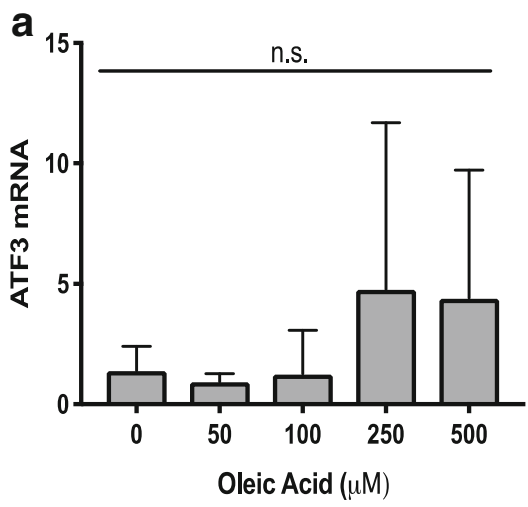

Fig. 3 Effect of OA treatment on ER stress transcripts. The effects of 50 $500-\mu \mathrm{M}$ OA treatment alone for $46 \mathrm{~h}$ on ATF3 and CHOP transcript levels in mouse blastocysts. ATF3 and CHOP mRNA levels were not concentrations; d) alleviated the significant decline in development of PA-treated 2-cell stage embryos to the blastocyst stage. Treatment with 100- $\mu \mathrm{M}$ PA increased the proportion of embryos displaying cell fragmentation and unequal blastomeres relative to controls (e controls; $\mathbf{f}$ PA treated). Co-culture of 2-cell embryos in 100- $\mu \mathrm{M}$ PA with OA resulted in improved embryo morphology $(\mathbf{g})$. Bars represent the mean percentage of embryos at each stage $+\mathrm{SD}$. Bars with different letters are statistically significant from one another. Scale bars are equal to $50 \mu \mathrm{m}$

OA (images not shown, Fig. 7C) did not differ significantly from untreated control embryos (Fig. 7Aa, Ba, and $\mathrm{C}$ ). Interestingly, we did observe that mitochondrial

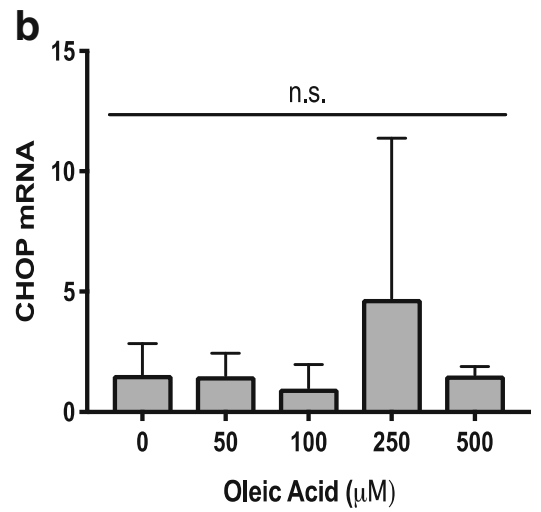

significantly affected by OA treatment at any dose (a, $\mathbf{b}, p>0.05 . n=3)$. Bars represent mean fold change in mRNA abundance relative to the control + SD 


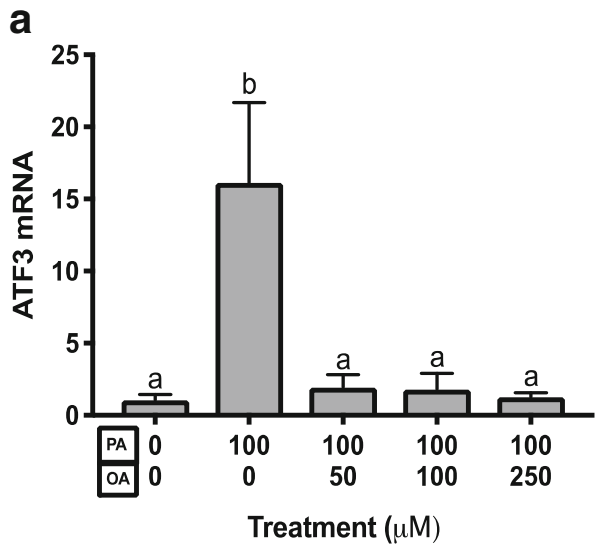

Fig. 4 Effect of PA and OA co-treatment on ER stress transcripts. The effects of exposure to $100-\mu \mathrm{M}$ PA treatment alone, and PA and OA combination treatments for $46 \mathrm{~h}$ on transcript levels of marker mRNAs representing ER stress pathways were assessed. In 100- $\mu \mathrm{M}$ PA-treated embryos, ATF3 transcript abundance increased significantly $(p<0.05$, $n=3$ ) to 15 fold the control levels, and CHOP transcript increased significantly $(p<0.05, n=3)$ to 5 fold the control levels (a, b). OA co-

superoxide levels were significantly lower $(p<0.05)$ in embryos exposed to $100-\mu \mathrm{M}$ PA in combination with $100-\mu \mathrm{M}$ or $250-\mu \mathrm{M}$ OA (Fig. 7Ac, Bc, and C). Thus, OA treatment displayed an ability to reduce basal levels and mitochondrial superoxide levels within in vitro cultured embryos.

\section{Discussion}

We have discovered that mouse oviductal PA concentrations are nearly twice as high as mouse uterine PA concentrations and are much higher than OA concentrations in these tissues. Treatment of 2-cell stage mouse embryos in vitro alone with

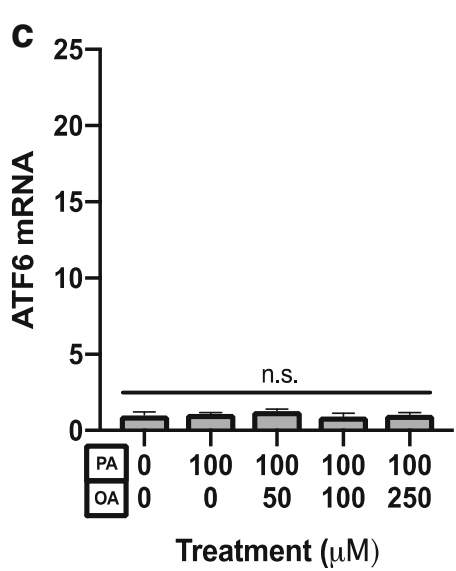

treatment at all doses alleviated the PA-induced increases in CHOP and ATF3 mRNA levels (a, b, $p<0.05, n=3)$. PA treatment $(100 \mu \mathrm{M})$ alone or in combination with OA did not significantly affect the relative levels of ATF6 mRNAs across all groups (c, $p>0.05, n=3$ ). Bars represent mean fold change in mRNA abundance relative to the control $+\mathrm{SD}$. Bars with different letters are statistically significant from one another

PA at lower than reproductive tract tissue concentrations disrupts preimplantation development to the blastocyst stage and is accompanied by elevated ER stress pathway transcript levels. In contrast, treatment with OA up to $500 \mu \mathrm{M}$ does not significantly affect development of 2-cell stage mouse embryos to the blastocyst stage; however, it increases LD accumulation and reduces mitochondrial ROS in early embryos. Most importantly, the addition of OA as a co-treatment with PA counters the negative developmental impact of PA alone as well as its impact on ER stress transcript levels. Collectively, our results suggest that mouse preimplantation embryos are exquisitely sensitive to external FFA levels, especially for PA. The early embryo appears to respond to this stress, as it does for many other stressors, in part, by
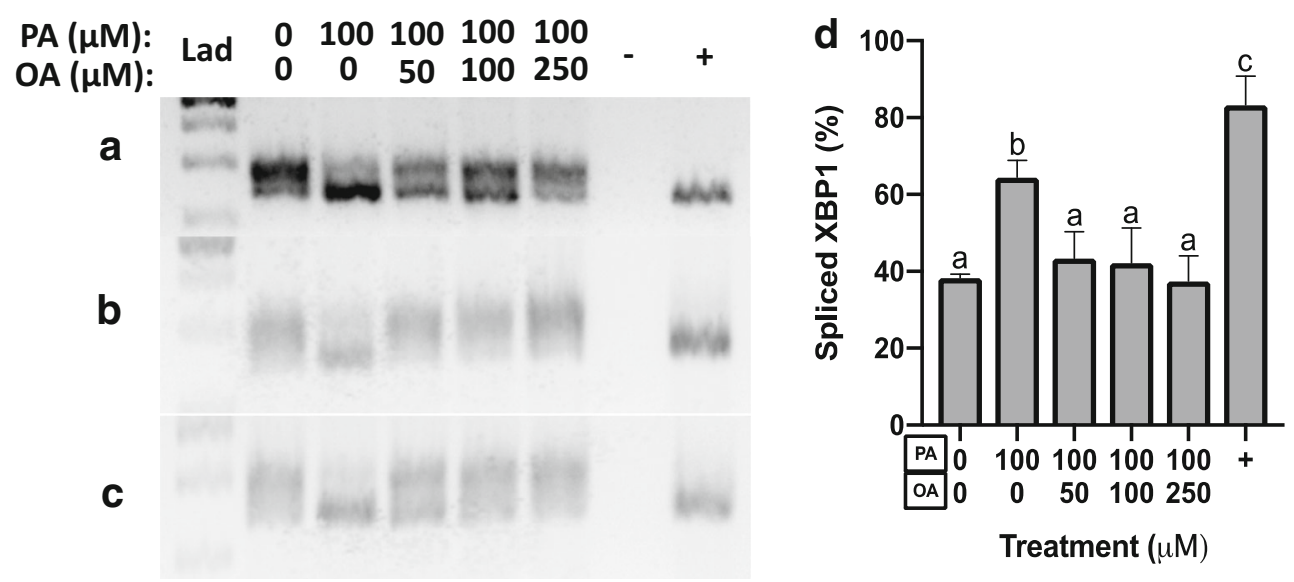

Fig. 5 Effect of PA and OA co-treatment on XBP1 splicing. To characterize effects to the IRE1 arm of the ER stress pathway, we measured effects of PA alone or with OA on the relative levels of spliced XBP1 mRNA. Treatment with $100-\mu$ M PA significantly $(p<$ $0.05, n=3)$ increased XBP1 mRNA splicing (A-D) relative to controls. XBP1 mRNA splicing was significantly reduced $(p<0.05, n=3)$ when

co-treatment with OA occurred (A-D). Controls included a no-cDNA negative control (-) and tunicamycin-treated embryo positive control $(+)$. A-C represent three biological replicates. Bars in D represent mean percentage of spliced XBP1 transcripts + SD. Bars with different letters are statistically significant from one another 

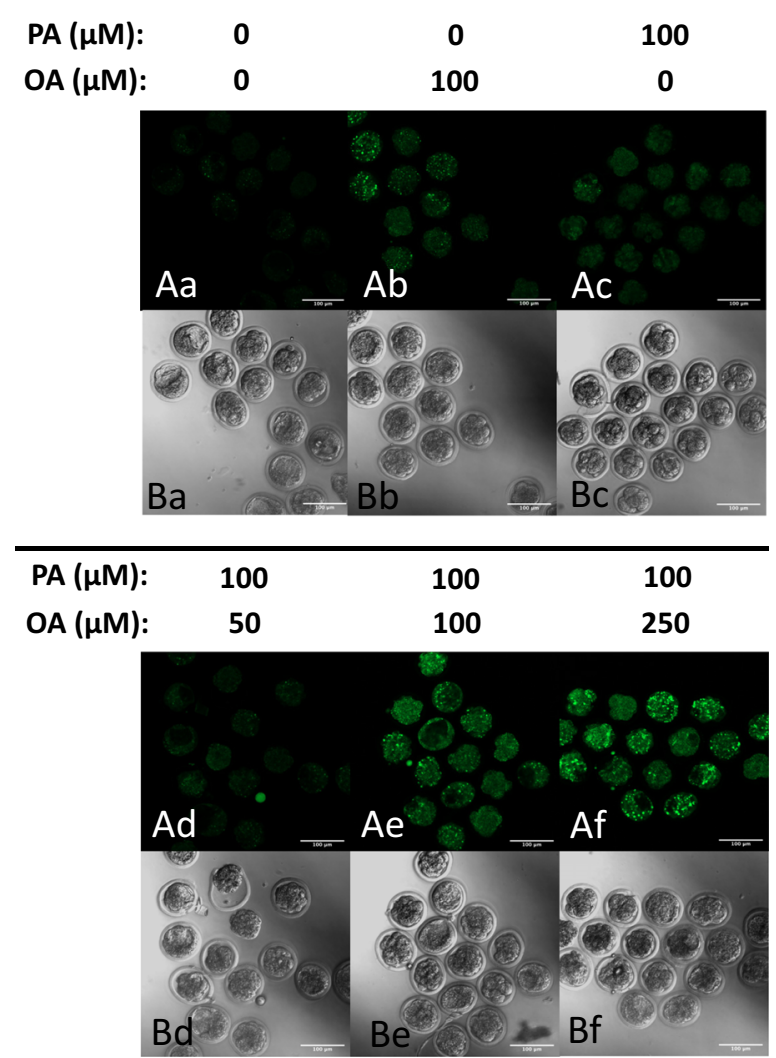

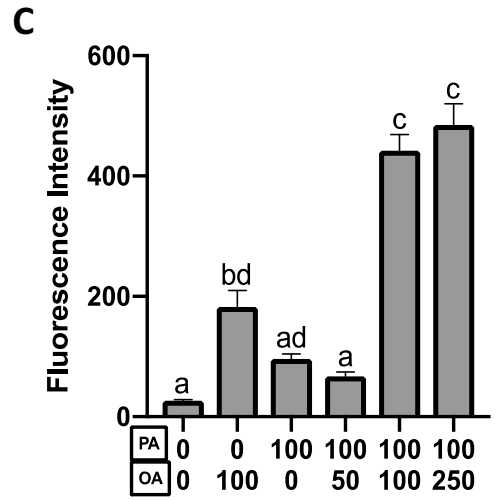

Treatment $(\mu \mathrm{M})$
Fig. 6 OA treatment increases lipid droplet levels. Compared with control media $(n=14)$, OA treatment alone $(100 \mu \mathrm{M}, n=12)$ significantly increased ( $p<0.05, \mathrm{Ab}, \mathrm{Bb}, \mathrm{C}) \mathrm{LD}$ content. PA treatment $(100 \mu \mathrm{M}, n=18)$ alone did not significantly affect $(p>0.05$, Ac, Bc, C) LD content. Co-treatment with $50-\mu \mathrm{M}$ OA $(n=13, \mathrm{Ad}, \mathrm{Bd}, \mathrm{C})$ did not significantly alter $\mathrm{LD}$ levels from control $(\mathrm{Aa}, \mathrm{Ba}, \mathrm{C})$ or PA alone (Ac, $\mathrm{Bc}, \mathrm{C})$. OA at $100(n=15)$ and $250(n=16) \mu \mathrm{M}$ significantly increased
( $p<0.05, \mathrm{Ae}, \mathrm{Be}, \mathrm{Af}, \mathrm{Bf}, \mathrm{C}) \mathrm{LD}$ levels 16 and 18 times greater than controls, respectively. Scale bars represent $100 \mu \mathrm{m}$. Bars in C represent mean BODIPY 493/503 fluorescence per embryo + standard error (SE). Data is presented in fluorescence units with background fluorescence subtracted. Bars with different letters are statistically significant from one another
PA ( $\mu \mathrm{M})$ :
0
100
0
100
$\mathrm{OA}(\mu \mathrm{M})$ :
0
100

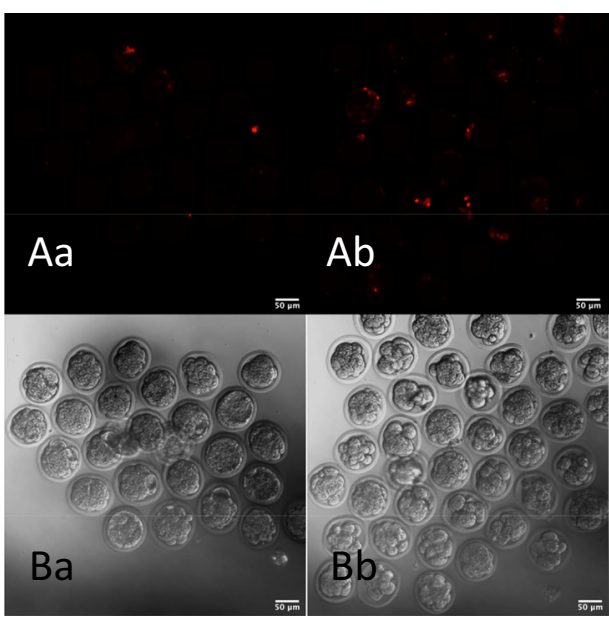

Fig. 7 OA reduces MitoSox Red Fluorescence. Mitochondrial superoxide produced by embryos exposed to PA treatment alone $(100 \mu \mathrm{M}, n=28)(\mathrm{Ab}, \mathrm{Bb}, \mathrm{C})$ or in combination with $50-\mu \mathrm{M}$ OA $(n=$ 24 , images not shown) did not differ significantly from untreated control embryos ( $n=19$, Aa, Ba, C). Mitochondrial superoxide levels were significantly lower in embryos exposed to $100-\mu \mathrm{M}$ PA in combination

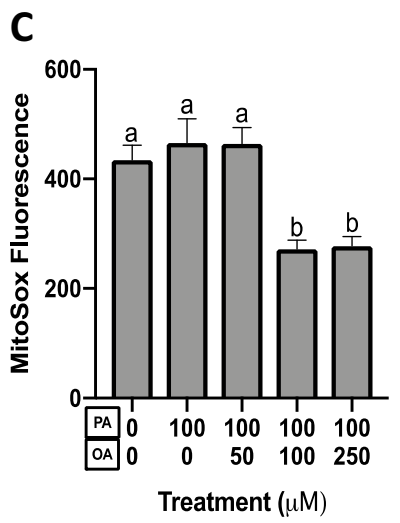

with $100-\mu \mathrm{M}(n=24, \mathrm{Ac}, \mathrm{Bc}, \mathrm{C})$ or $250-\mu \mathrm{M}$ OA $(n=24$, images not shown). Bars in $\mathrm{C}$ represent mean MitoSox Red fluorescence per embryo + standard error (SE). Data are presented in fluorescence units with background fluorescence subtracted. Bars with different letters are statistically significant from one another. Scale bars represent $50 \mu \mathrm{m}$ 
upregulating the ER stress pathways. However, PA levels may exceed this adaptive capacity, resulting in impaired preimplantation development. Our results are especially poignant for obese patients seeking fertility treatment, as they bring into focus the possibility of an obesity-conditioned reproductive tract actively suppressing preimplantation development and consequently pregnancy. Research must identify approaches in which the debilitating effects of PA exposure may be alleviated.

The literature has established that PA and OA have differential effects in many tissues. PA is generally viewed as being pro-apoptotic, while OA has beneficial and protective effects against PA [15, 33, 34]. For example, a recent review reported that PA is pro-inflammatory and induces ER stress [35]. However, the negative effects of PA can be overcome by relatively lower concentrations of OA in many tissues, including hepatocytes and pancreatic $\beta$ cells [35]. PA reduces insulin sensitivity in hepatocytes [15] and skeletal muscle [36], and thereby contributes to the development of type 2 diabetes mellitus (T2DM). Conversely, OA is protective against insulin resistance and T2DM [35]. PA dose-dependently increased podocyte ROS production and apoptosis, suggesting its contribution to podocyte loss in the kidney and subsequent development of diabetic nephropathy [37]. When administered intraperitoneally, PA is linked to behavioral abnormalities, such as anxiety-like symptoms in mice [38]. Studies indicate that PA exerts its negative effects through a variety of mechanisms, including alterations to cellular membranes [39], ER stress [34, 40-46], diacylglycerol (DAG) accumulation [47], mitochondrial dysfunction, and ROS production [48, 49]. These effects, which are collectively called "lipotoxicity," ultimately result in ER stress and subsequent apoptosis if the stress is not alleviated.

ER stress occurs in response to an accumulation of unfolded or misfolded proteins in the ER. The UPR pathway is activated in an attempt to alleviate this stress [50]. If unable to establish homeostasis, the UPR results in apoptosis [51]. Differential effects of physiologically relevant doses of PA and OA on ER stress were observed in hepatoma cells, where PA induced ER stress and OA did not [42, 52]. In primary neonatal cardiomyocytes, PA induced both ER stress and apoptosis, whereas OA alone did not [34]. In rat liver hepatoma cells, 500- $\mu \mathrm{M}$ PA treatment induced ER stress and elevated PERK and IRE1 $\alpha$ phosphorylation, and XBP1 splicing upon PA exposure [42]. Given the close relationship in other tissues between PA exposure and ER stress activation [34, 35, 41-47], we assessed the UPR and ER stress pathways in our embryos using RT-PCR for XBP1 splicing and quantitative RT-PCR for CHOP, ATF3, and ATF6. Thus, in total, we investigated the effects of PA and OA treatment on all three arms of the UPR, with ATF3 and CHOP falling under the PERK arm, XBP1 splicing a marker of the IRE1 $\alpha$ arm, and ATF6 falling under its own arm. As is consistent with previous studies [24-27, 34, 53], PA altered ER stress pathway transcripts but OA did not. However, a key limitation of our outcomes, is that UPR and ER stress pathway members are regulated via posttranslational modifications, such as phosphorylation of PERK, IRE1, and ATF6. Protein phosphorylation can be assessed through western blotting; however, the low protein abundance in mouse preimplantation embryos makes these experiments technically challenging to successfully perform and requires large embryo pools to effectively apply. In addition, we cannot conclude that the changes we have observed "cause" the developmental blockade observed following PA treatment. We are simply reporting key observations made in embryo pools following $46 \mathrm{~h}$ of treatment. We believe that these observations are the first to indicate that exposure to elevated PA may affect ER stress pathway constituent expression and that the addition of OA significantly reverses that occurrence. There are many more experimental designs and time course experiments that must be conducted to fully understand this outcome, and we are very interested in pursuing outcomes to those stage-specific effects in future experiments. Our results are consistent with the growing conclusion that OA is protective against PA's effects, specifically in that it alleviates PA-induced ER stress in mouse preimplantation embryos [22-27, 34].

A recent review by Fayezi et al. [54] outlined the most likely mechanisms through which OA exerts its protective effects. These included but were not limited to 1) altering triacylglycerol (TAG) synthesis, 2) reducing oxidative stress, and 3) altering energy production. Fatty acids (FAs), either bound to albumin or contained in lipoproteins, are found extracellularly. Once released, FAs enter the cell where they are conjugated to CoA [55]. A series of enzymatically catalyzed reactions in the ER allows for the formation of DAGs, which can then form TAGs $[55,56]$. Conversion of DAG to TAG is the final step of TAG formation and is catalyzed by diacylglycerol acyltransferase (DGAT) enzymes DGAT1 and DGAT2 [56]. PA and OA differentially affect LD accumulation. Since OA is steatotic and causes lipid accumulation, exposure to OA increases LD number [47, 54]. LDs are made up of a phospholipid monolayer surrounding a neutral lipid core mainly consisting of TAGs [55]. Piccolis et al. [44] reported that when human leukemia cells were exposed to PA, a primary mechanism responsible for lipotoxicity was ER stress, which was associated with an accumulation of PA and DAGs in the cells. In cardiomyoblasts, PA treatment reduced LD levels, whereas OA increased LD accumulation [47]. This decrease in LDs with PA treatment was not due to a lower supply of neutral lipid, as more PA accumulated in the cells than OA, and fatty acid oxidation was reduced with PA exposure [47]. The investigators concluded that the reductions in LDs with PA were due to PA storage as DAGs, whereas OA is largely stored as TAGs [47]. Accumulation of PA in the ER likely contributes to induction of ER stress, activation of 
the UPR, and apoptosis should the ER stress not be relieved. In our study, OA, but not PA, induced lipid droplet accumulation in mouse preimplantation embryos. Inclusion of OA concentrations equal to or higher than the 100- $\mu \mathrm{M}$ PA in coculture resulted in lipid droplet accumulation that was significantly higher than control, PA-only, or OA-only treated embryos. When quantified, there was no difference in BODIPY fluorescence in PA-treated embryo from controls. This outcome seems reasonable, as we suggest the PA could be accumulating as DAGs and would not accumulate within LDs. Collectively, our findings suggest that OA directs accumulation of TAGs within cytoplasmic lipid droplets during mouse preimplantation development. Given the similarity of our outcomes to studies applied to other tissues, we suggest that there is reasonable likelihood for common mechanistic events arising during preimplantation development.

Studies have established that PA treatment often results in mitochondrial dysfunction [57-62]. To consider this effect in preimplantation embryos, mitochondrial superoxide levels in embryos exposed to PA alone or in combination with OA were quantified. When OA was added to skeletal myotubes cultured in PA, the PA-induced increase in MitoSox Red fluorescence was dampened. Interestingly, in our study, the embryos cultured in control, PA alone, or PA co-cultured with 50- $\mu \mathrm{M}$ OA did not vary in the levels of detectable mitochondrial superoxide. Compared with these groups, embryos co-cultured with PA and $100-$ or $250-\mu \mathrm{M}$ OA produced significantly less mitochondrial superoxide. We propose that the $100-\mu \mathrm{M}$ PA treatment we employed was not enough to elevate mitochondrial ROS. Clearly, however, elevated OA concentrations (100 or $250 \mu \mathrm{M})$ have the capacity to reduce mitochondrial ROS levels even below that of basal culture-induced levels. Thus, it is possible that adding OA alone to the culture medium may be beneficial for supporting preimplantation embryo mitochondrial function. However, the differences in mitochondrial superoxide levels may not be indicative of mitochondrial superoxide production.

Overall, our outcomes essentially mirror those observed regarding $\mathrm{PA}$ and OA's effects across many different tissues; however, the effect of $\mathrm{PA}$ and $\mathrm{OA}$ in the reproductive tract, specifically during preimplantation embryo development, has not been extensively investigated and defined. The timing of preimplantation embryo development is a key measure of embryo developmental competence [62]. Developmental competence is also often assessed by embryo cell number [62]. Although we did not measure blastocyst cell number, the fact that embryos exposed to OA alone or in combination with PA were able to reach the blastocyst stage within a normal culture period is indicative of developmental competence and likely capacity to initiate a pregnancy. The significantly decreased progression throughout preimplantation development that we observed following PA treatment is an ominous sign and is highly suggestive of decreased embryo viability even if the blastocyst stage is reached. Additionally, morphological assessment of PA-treated embryos displayed uneven blastomeres and cell fragmentation, both of which are signs of reduced embryo developmental competence $[62,63]$. These morphological changes did not occur with PA and OA co-treatment, suggesting that mouse embryos that were exposed to OA may have greater adaptive ability. When PA treatment time was reduced to $24 \mathrm{~h}$, we observed normal development to the blastocyst stage following $48 \mathrm{~h}$ of post-treatment culture in control medium. This indicates that 24-h exposure to PA delayed the embryos' development; however, removal of PA and additional culture time allowed the embryos to overcome this delay. We believe this to be an important finding, as it suggests that removing embryos from a high fatty acid environment may improve their development. Further research must be conducted to investigate the underlying mechanisms controlling the developmental blockade resulting from PA treatment.

In conclusion our outcomes have revealed that PA treatment reduces blastocyst development and alters ER stress pathway transcript levels. OA co-treatment with PA not only limits PA effects on blastocyst development and ER stress transcript levels but also increases lipid droplet accumulation and reduces mitochondrial stress. Thus, preimplantation embryos do employ stress response mechanisms to avoid the deleterious effects of PA exposure, but their protective ability may be overwhelmed by elevated PA levels. This information is vital to our understanding of the influence of obesity on human fertility. Investigating the extent of OA's protective effects using different culture concentrations and times of exposure could contribute to optimizing culture environments for all preimplantation embryo culture systems, including that of the human.

Acknowledgments We are grateful to Dr. Nicole Edwards and Zuleika (CL) Leung for assistance with embryo collections and data organization.

Funding Information This work was supported by a project grant from the Canadian Institutes of Health Research (CHRI) Canada to DHB, BAR, and AJW. MDY was supported by an Ontario Graduate Scholarship.

\section{Compliance with Ethical Standards}

All experiments were performed using CD-1 mice from Charles River Laboratories (Saint-Constant, QC). All mice were handled according to the Canadian Council on Animal Care and Western University's Animal Care and Use Policies (protocol \#: 2018-075 to Dr. Andrew J. Watson). Mice were housed using conventional housing with a 12-h light/dark cycle and access to standard mouse chow ad libitum.

Conflict of Interest The authors declare that they have no conflict of interest. 
Open Access This article is licensed under a Creative Commons Attribution 4.0 International License, which permits use, sharing, adaptation, distribution and reproduction in any medium or format, as long as you give appropriate credit to the original author(s) and the source, provide a link to the Creative Commons licence, and indicate if changes were made. The images or other third party material in this article are included in the article's Creative Commons licence, unless indicated otherwise in a credit line to the material. If material is not included in the article's Creative Commons licence and your intended use is not permitted by statutory regulation or exceeds the permitted use, you will need to obtain permission directly from the copyright holder. To view a copy of this licence, visit http://creativecommons.org/licenses/by/4.0/.

\section{References}

1. World Health Organization. Obesity and overweight. Available at: https://www.who.int/news-room/fact-sheets/detail/obesity-andoverweight. Accessed 23 Apr 2019.

2. Statistics Canada. Body mass index, overweight or obese, self-reported, adult, age groups (18 years and older). 2018. Available at: https://www 150. statcan.gc.ca/t1/tb11/en/tv.action?pid= 1310009620. Accessed Apr 2019.

3. Palmer NO, Bakos HW, Fullston T, Lane M. Impact of obesity on male fertility, sperm function and molecular composition. Spermatogenesis. 2012;2(4):253-63.

4. Silvestris E, De Pergola G, Rosania R, Loverro G. Obesity as disruptor of the female fertility. Reprod Biol Endocrinol. 2018;16(1):22.

5. Maheshwari A, Stofberg L, Bhattacharya S. Effect of overweight and obesity on assisted reproductive technology-a systematic review. Hum Reprod Update. 2007;13(5):433-44.

6. Jungheim ES, Travieso JL, Hopeman MM. Weighing the impact of obesity on female reproductive function and fertility. Nutr Rev. 2013;71(Supp11):S3-8.

7. Luke B, Brown MB, Missmer SA, Bukulmez O, Leach R, Stern JE. The effect of increasing obesity on the response to and outcome of assisted reproductive technology: a national study. Fertil Steril. 2011;96(4):820-5

8. Cui N, Wang $H$, Zhang J, et al. Impact of body mass index on outcomes of in vitro fertilization/intracytoplasmic sperm injection among polycystic ovarian syndrome patients. Cell Physiol Biochem. 2016;39(5):1723-34.

9. Fedorcsák P, Dale PO, Storeng R, Ertzeid G, Bjercke S, Oldereid N, et al. Impact of overweight and underweight on assisted reproduction treatment. Hum Reprod. 2004;19(11):2523-8.

10. Bailey AP, Hawkins LK, Missmer SA, Correia KF, Yanushpolsky EH. Effect of body mass index on clinical manifestations in patients with polycystic ovary syndrome. Am J Obstet Gynecol. 2014;211(2):163e1-6.

11. Lashen H, Fear K, Sturdee DW. Obesity is associated with increased risk of first trimester and recurrent miscarriage: matched case-control study. Hum Reprod. 2004;19(7):1644-6.

12. Blache D, Bourdon E, Salloignon P, Lucchi G, Ducoroy P, Petit $\mathrm{JM}$, et al. Glycated albumin with loss of fatty acid binding capacity contributes to enhanced arachidonate oxygenation and platelet hyperactivity: relevance in patients with type 2 diabetes. Diabetes. 2015;64(3):960-72.

13. Karpe F, Dickmann JR, Frayn KN. Fatty acids, obesity, and insulin resistance: time for a reevaluation. Diabetes. 2011;60(10):2441-9.

14. Abdelmagid SA, Clarke SE, Roke K, et al. Comprehensive profiling of plasma fatty acid concentrations in young healthy Canadian adults. PLoS One. 2015;10(2):1-16.
15. Ricchi M, Odoardi MR, Carulli L, Anzivino C, Ballestri S, Pinetti A, et al. Differential effect of oleic and palmitic acid on lipid accumulation and apoptosis in cultured hepatocytes. J Gastroenterol Hepatol. 2009;24(5):830-40.

16. Valckx SDM, Arias-Alvarez M, De Pauw I, et al. Fatty acid composition of the follicular fluid of normal weight, overweight and obese women undergoing assisted reproductive treatment: a descriptive cross-sectional study. Reprod Biol Endocrinol. 2014;12: 13.

17. Bakke SS, Moro C, Nikolic N, et al. Palmitic acid follows a different metabolic pathway than oleic acid in human skeletal muscle cells; lower lipolysis rate despite an increased level of adipose triglyceride lipase. Biochim Biophys Acta. 2012;182(10):1323-33.

18. Ma W, Wu JH, Wang Q, et al. Prospective association of fatty acids in the de novo lipogenesis pathway with risk of type 2 diabetes: the Cardiovascular Health Study. Am J Clin Nutr. 2015;101(1):15363.

19. Luzzo KM, Wang Q, Purcell SH, Chi M, Jimenez PT, Grindler N, et al. High fat diet induced developmental defects in the mouse: oocyte meiotic aneuploidy and fetal growth retardation/brain defects. PLoS One. 2012;7(11):e49217.

20. Jungheim ES, Macones GA, Odem RR, Patterson BW, Lanzendorf SE, Ratts VS, et al. Associations between free fatty acids, cumulus oocyte complex morphology and ovarian function during in vitro fertilization. Fertil Steril. 2011;95(6):1970-4.

21. Sutton-McDowall ML, Wu LL, Purdey M, et al. Non-esterified fatty acid-induced endoplasmic reticulum stress in cattle cumulus oocyte complexes alters cell metabolism and developmental competence. Biol Reprod. 2016;94(1):23.

22. Lin T, Lee JE, Kang JW, Shin H, Lee J, Jin D. Endoplasmic reticulum (ER) stress and unfolded protein response (UPR) in mammalian oocyte maturation and preimplantation development. Int J Mol Sci. 2019;20:409.

23. Latham KE. Stress signaling in mammalian oocytes and embryos: a basis for intervention and improvement of outcomes. Cell Tissus Res. 2016;363:159-67.

24. Abraham T, Pin CL, Watson AJ. Embryo collection induces transient activation of XBP1 arm of the ER stress response while embryo vitrification does not. Mol Hum Reprod. 2012;18(5):229-42.

25. Luo S, Mao C, Lee B, Mao C, Lee B, Lee AS. GRP78/BiP is required for cell proliferation and protecting the inner cell mass from apoptosis during early mouse embryonic development. Mol Cell Biol. 2006;26:5688-97.

26. Kim SK, Kim YK, Lee AS, et al. Expression of the glucoseregulated proteins (GRP94 and GRP78) in differentiated and undifferentiated mouse embryonic cells and the use of the GRP78 promoter as an expression system in embryonic cells. Differentiation. 1990;42:153-9.

27. Zhang JY, Diao YF, Kim HR, Jin DI. Inhibition of endoplasmic reticulum stress improves mouse embryo development. PLoS One. 2012;7:e40433.

28. Calder M, Chan YM, Rai R, et al. Implantation failure in female kiss1-/- mice is independent of their hypogonadic state and can be partially rescued by leukemia inhibitory factor. Endocrinology. 2014;155(8):3065-78.

29. Edwards NA, Watson AJ, Betts DH. P66Shc, a key regulator of metabolism and mitochondrial ROS production, is dysregulated by mouse embryo culture. Mol Hum Reprod. 2016;22(9):634-47.

30. Calder MD, Edwards NA, Betts DH, Watson AJ. Treatment with AICAR inhibits blastocyst development, trophectoderm differentiation and tight junction formation and function in mice. Mol Hum Reprod. 2017;23(11):771-85.

31. Abdullahi A, Stanojcic M, Parousis A, Patsouris D, Jeschke MG. Modeling acute ER stress in vivo and in vitro. Shock. 2017;47(4): 506-13. 
32. Sommer C, Straehle C, Kothe U, Hamprechet FA. ilastik: Interactive learning and segmentation toolkit. 2011 in Eighth IEEE International Symposium on Biomedical Imaging (ISBI 2011). Proceedings 230-233. https://doi.org/10.1109/ISBI.2011. 5872394.

33. Peng G, Li L, Liu Y, Pu J, Zhang S, Yu J, et al. Oleate blocks palmitate-induced abnormal lipid distribution, endoplasmic reticulum expansion and stress, and insulin resistance in skeletal muscle. Endocrinology. 2011;152(6):2206-18.

34. Haffar T, Berube-Simard F, Bousette N. Impaired fatty acid oxidation as a cause for lipotoxicity in cardiomyocytes. Biochem Biophys Res Commun. 2015;468(1-2):73-8.

35. Palomer X, Pizarro-Delgado J, Barroso E, Vázquez-Carrera M. Palmitic and oleic acid: the yin and yang of fatty acids in type 2 diabetes mellitus. Trends Endocrinol Metab. 2018;29(3):178-90.

36. Alkhateeb H, Qnais E. Preventive effect of oleate on palmitateinduced insulin resistance in skeletal muscle and its mechanism of action. J Physiol Biochem. 2017;73(4):605-12.

37. Jiang XS, Chen XM, Wan JM, Gui HB, Ruan XZ, Du XG. Autophagy protects against palmitic acid-induced apoptosis in podocytes in vitro. Sci Rep. 2017;22(7):42764. https://doi.org/10. 1038/srep42764.

38. Moon ML, Joesting JJ, Lawson MA, Chiu GS, Blevins NA, Kwakwa KA, et al. The saturated fatty acid, palmitic acid, induces anxiety-like behavior in mice. Metabolism. 2014;63(9):1131-40.

39. Ly LD, Xu S, Choi SK, et al. Oxidative stress and calcium dysregulation by palmitate in type 2 diabetes. Exp Mol Med. 2017;49(2): e.291.

40. Zhang Y, Miao L, Zhang H, Wu G, Zhang Z, Lv J. Chlorogenic acid against palmitic acid in endoplasmic reticulum stress-mediated apoptosis resulting in protective effect of primary rat hepatocytes. Lipids Health Dis. 2018;17(1):270.

41. Zhang Y, Xue R, Zhang Z, Yang X, Shi H. Palmitic and linoleic acids induce ER stress and apoptosis in hepatoma cells. Lipids Health Dis. 2012;11:1.

42. Wei Y, Wang D, Topczewski F, Pagliassotti MJ. Saturated fatty acids induce endoplasmic reticulum stress and apoptosis independently of ceramide in liver cells. Am J Physiol Endocrinol Metab. 2006;291(2):275-81.

43. Guan G, Lei L, Lv Q, Gong Y, Yang L. Curcumin attenuates palmitic acid-induced cell apoptosis by inhibiting endoplasmic reticulum stress in H9C2 cardiomyocytes. Hum Exp Toxicol. 2019;38(6):655-64. https://doi.org/10.1177/0960327119836222.

44. Piccolis M, Bond LM, Kampmann M, Pulimeno P, Chitraju C, Jayson CBK, et al. Probing the global cellular responses to lipotoxicity caused by saturated fatty acids. Mol Cell. 2019;74(1): 32-44.

45. Guo W, Wong S, Xie W, Lei T, Luo Z. Palmitate modulates intracellular signaling, induces endoplasmic reticulum stress, and causes apoptosis in mouse 3T3-L1 and rat primary preadipocytes. Am J Physiol Endocrinol Metab. 2007;293(2):576-86.

46. Kwak HJ, Choi HE, Jang J, Park SK, Bae YA, Cheon HG. Bortezomib attenuates palmitic acid-induced ER stress, inflammation and insulin resistance in myotubes via AMPK dependent mechanism. Cell Signal. 2016;28(8):788-97.

47. Akoumi A, Haffar T, Mousterji M, Kiss RS, Bousette N. Palmitate mediated diacylglycerol accumulation causes endoplasmic reticulum stress, Plin2 degradation, and cell death in $\mathrm{H} 9 \mathrm{C} 2$ cardiomyoblasts. Exp Cell Res. 2017;354(2):85-94.
48. Joseph LC, Barca E, Subramanyam P, Komrowski M, Pajvani U, Colecraft HM, et al. Inhibition of NAPDH oxidase 2 (NOX2) prevents oxidative stress and mitochondrial abnormalities caused by saturated fat in cardiomyocytes. PLoS One. 2016;11(1):e0145750. https://doi.org/10.1371/journal.pone.0145750.

49. Lee H, Lim JY, Choi SJ. Oleate prevents palmitate-induced atrophy via modulation of mitochondrial ROS production in skeletal myotubes. Oxidative Med Cell Longev. 2017. https://doi.org/10. 1155/2017/2739721.

50. Schroder M, Kaufman RJ. ER stress and the unfolded protein response. Mutat Res. 2005;569(1-2):29-63.

51. Flamment M, Hajduch E, Ferré P, Foufelle F. New insights into ER stress-induced insulin resistance. Trends Endocrinol Metab. 2012;23(8):381-90.

52. Hetherington AM, Sawyez CG, Zilberman E, Stoianov AM, Robson DL, Borradaile NM. Differential lipotoxic effects of palmitate and oleate in activated human hepatic stellate cells and epithelial hepatoma cells. Cell Physiol Biochem. 2016;39(4):1648-62.

53. Gehrmann W, Wurdemann W, Piotz T, Jorns A, Lenzen S, Elsner M. Antagonism between saturated and unsaturated fatty acids in ROS mediated lipotoxicity in rat insulin-producing cells. Cell Physiol Biochem. 2015;36(3):852-65.

54. Fayezi S, Leroy JLMR, Ghaffari Novin M, Darabi M. Oleic acid in the modulation of oocyte and preimplantation embryo development. Zygote. 2017;26(1):1-13.

55. Guo Y, Cordes KR, Farese RV Jr, Walther TC. Lipid droplets at a glance. J Cell Sci. 2009;122(Pt6):749-52.

56. Ahmadian M, Duncan RE, Jaworski K, Sarkadi-Nagy E, Sul HS. Triacylglycerol metabolism in adipose tissue. Futur Lipidol. 2007;2(2):229-37.

57. Broniarek I, Koziel A, Jarmuszkiewicz W. The effect of chronic exposure to high palmitic acid concentrations on the aerobic metabolism of human endothelial EA.hy926 cells. Pflugers Arch. 2016;468(9):1541-54.

58. Itami N, Shirasuna K, Kuwayama T, Iwata H. Palmitic acid induces ceramide accumulation, mitochondrial protein hyperacetylation, and mitochondrial dysfunction in porcine oocytes. Biol Reprod. 2018;98(5):644-53.

59. Lee H, Lim JY, Choi SJ. Oleate prevents palmitate-induced atrophy via modulation of mitochondrial ROS production in skeletal myotubes. Oxidative Med Cell Longev. 2017;2017:2739721.

60. Lee E, Choi J, Lee HS. Palmitate induces mitochondrial superoxide generation and activates AMPK in podocytes. J Cell Physiol. 2017;232(12):3209-17.

61. Ighodaro OM, Akinloye OA. First line defence antioxidantssuperoxide dismutase (SOD), catalase (CAT) and glutathione peroxidase (GPX): their fundamental role in the entire antioxidant defence grid. Alexandria J Med. 2018;54(4):287-93.

62. Newmark JA, Wagner WC 2nd, Chang C, et al. Determination of the number of cells in preimplantation embryos by using noninvasive optical quadrature microscopy in conjunction with differential interference contrast microscopy. Microsc Microanal. 2007;13(2): $118-27$.

63. Lundin K, Ahlström A. Quality control and standardization of embryo morphology scoring and viability markers. Reprod BioMed Online. 2015;31(4):459-71.

Publisher's Note Springer Nature remains neutral with regard to jurisdictional claims in published maps and institutional affiliations. 